\title{
Genetic analysis of days open in beef cattle
}

\author{
F. Goyache ${ }^{a, *}$, J.P. Gutiérrez ${ }^{b}$ I. Fernández ${ }^{a}$, L.J. Royo ${ }^{a}$, I. Álvarez ${ }^{a}$

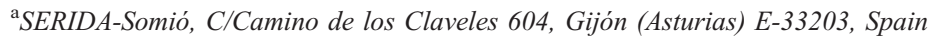 \\ ${ }^{\mathrm{b}}$ Universidad Complutense de Madrid, Departamento de Producción Animal, Facultad de Veterinaria, Madrid E-28040, Spain
}

\begin{abstract}
The aim of this work was to analyse the genetic parameters affecting days open (DO) in beef cattle to evaluate its potential as criterion of selection. The present study characterises DO as a trait with considerable genetic variability, relative to that usually found for reproduction traits, especially for heifers and second calving cows. The estimates of heritability for the trait ranged from 0.091 for cows with 10 or more calvings to 0.197 for second calving cows. The genetic correlations estimated for DO in different parities are situated between 0.9 and 1 , showing that the genes affecting the trait are substantially the same across parities of the dam. A substantial permanent environment (around 9\%) seems to affect DO performance. Permanent environmental factors seem to be especially important in younger cows. Genetic correlation between DO and calving interval was positive and very high (1.0), while those between DO and gestation length and calving date were negative from low to moderate $(-0.089$ and -0.308 , respectively). DO can be used in improvement programs of beef cattle as an early indicator of reproductive performance of the cow.
\end{abstract}

Keywords: Beef cattle; Asturiana de los Valles; Days open; Fertility; Heritability; Genetic correlation

\section{Introduction}

In dairy cattle, breeders pay a great deal of attention to days from calving to conception, also called days open (DO), because despite its low heritability, this trait seems to be clearly related to the cow's reproductive performance and profitability, as well as to its lactation yield (Freeman, 1984;
Philipsson, 1981; Kirkpatrick, 1998). However, DO has not been used in beef cattle and there are virtually no published references on genetic analysis of this trait. Performance recording usually does not include the date of fertile mating, as paddock matings are most frequent and artificial insemination is, in general, scarcely used. In Europe there, are various beef cattle breeds, such as Asturiana de los Valles, exploited in production systems including small-sized farms, without restricted breeding seasons and with widespread use of artificial insemination (Goyache et al., 1995; Gutiérrez et al., 1997; Gutiérrez and Goyache, 2002). 
In these cases, farmers can supervise individual matings and data on DO become reliable. Because the time needed to obtain DO scores is less than that needed to obtain other traits such as calving intervals, the use of DO in selection for reproductive performance in beef cattle would be justified. However, selection on female fertility from measurements taken at an early age is meaningful only when the relationship with fertility at an older age is high. Hence, the possibility suggested in dairy cattle (Jansen et al., 1987), that different genes may be expressed in different parities of the dam, should be tested. The aim of this work was to estimate the genetic factors affecting DO to assess its use in beef cattle improvement programs by analysing a sample of field data from the Asturiana de los Valles breed. To attain this objective, the genetic parameters affecting DO at different ages of the cow and the genetic relationships between DO and calving interval (CI), gestation length (GL), and calving date (CD) were analysed.

\section{Materials and methods}

Data were obtained from the performance recording database (the CORECA database) implemented by the Regional Government of Principado de Asturias, through the Asturiana de los Valles Breeders Association (ASEAVA). Asturiana de los Valles is exploited mostly in traditional conditions in the mountains of the north of Spain. Performance recording is based on nuclei, grouping farms according to their proximity, and their production system arising from the small size of the farms (Gutiérrez et al., 1997; Goyache et al., 2003). DO was calculated as the days from calving to the last observed mating date. DO records were only analysed when the available mating date produced a subsequent calving date within the range of 269-305 days of gestation length (Goyache and Gutiérrez, 2001) and from 290 to 630 days of calving interval (Goyache et al., 1995; Goyache and Gutiérrez, 2001; Gutiérrez et al., 2002). Records were deleted in all cases of uncertain calving number. The analysed database finally included 21,349 DO records from 9379 cows. Pedigree information included 2276 additional animals, with 1181 of them being sires. Thus, 11,655 animals were involved in the estimation of genetic parameters. Because of small average farm size, maintenance of sires is costly, leading to a wide use of artificial insemination (about 25\%, from $9 \%$ to $57 \%$ depending on areas) (Gutiérrez et al., 1997). Consequently, good genetic connections between herds were achieved (Gutiérrez and Goyache, 2002; Goyache et al., 2003). Up to 284 of the 1074 sires of dams producing data $(26 \%)$ had daughters in two or more nuclei. The number of artificial insemination sires showing progeny groups with 30 or more daughters and the total number of daughters of these sires were: 22 sires and 1451 daughters. Additionally, calving dates were also obtained from dams included in the genetic analysis of DO. Following Gutiérrez et al. (2002), CD was calculated as the deviation of the actual calving date from April 1 for the first calving season or October 1 for the second calving season. When a dam began her reproductive career in a given calving season, her corresponding CDs were calculated with respect to the reference date of this calving season, regardless of the subsequent actual calving dates. When fertile mating date and more than one calving date were available from a dam, GL and CI, respectively, were calculated within the admitted ranges described above. Finally, 34,409 CI records, 43,467 GL records, and 48,139 CD records were available.

Genetic parameters affecting DO were analysed via an REML procedure applied to a mixed linear model including the animal additive genetic effect $(u)$ considered as a random variable $(u \sim N(0, A \sigma 2 u)$. All runs were carried out using the DF-REML program (Meyer, 1997). As a consequence of prior analysis (Gutiérrez et al., 2003), three environmental factors were identified to have significant influence on DO: nucleus by year of calving, season of calving (from January 1 to July 31, and from August 1 to December 31 ), and age of the cow in years at previous calving coded in five levels: 2 years for cows less than 1003 days old at calving, 3 years for cows between 1003 and 1338 days old, 4 years between 1339 and 1703 days old, 5 years between 1704 and 3926 days old, and 6 years for cows older than 3926 days. Because environmental factors having significant influence on DO were consistent with those used to analyse other reproductive traits in previous works (Goyache and Gutiérrez, 2001; Gutiérrez et al., 2002), they were used for all the traits analysed in the present study. The models fitted to genetic analysis included as 
fixed effects: nucleus by year of calving of the dam as a comparison group (469 levels for DO, 493 for CI, and 563 levels for both GL and CD), season of calving (two levels), and age of the cow in years at previous calving (five levels). Throughout the paper (following Gutiérrez et al., 2003), the calvings of the dam were coded in four levels: first calving, second calving, from third to ninth calvings, and 10 or more calvings.

Five different models were fitted to ascertain: (a) the importance of both genetic and permanent environmental effects on DO (models 1 and 2); (b) the correlations between genetic and permanent environmental factors affecting DO across parities (models 4 and 5); and (c) the genetic correlation of DO with other traits (model 5). As regards random effects, differences between models are:

- Model 1: univariate animal model including the additive genetic effect $(u)$, the permanent environment $(c)$, and the residual $(e)$, with the additive genetic effect $(u)$ being the only random effect dependent on the relationship matrix.

- Model 2: like model 1, but including the permanent environment $(c)$.

- Model 3: multivariate animal model considering DO as different correlated traits for first calving, second calving, from third to ninth calvings, and for 10 or more calvings, and including the additive genetic effects $(u)$ and the covariance between these $\left(\operatorname{cov}_{(u u)}\right)$ as dependent on the relationship matrix.
Table 2

Genetic $(u)$, permanent environment $(c)$, error (e), and phenotypic ( $p$ ) variances, heritability, genetic covariances (on diagonal), and genetic correlation (below diagonal) for DO in the Asturiana de los Valles breed analysed by means of models 1 and 2

\begin{tabular}{lllllll}
\hline & $\operatorname{Var}_{(u)}$ & $\operatorname{Var}_{(c)}$ & $\operatorname{Var}_{(e)}$ & $\operatorname{Var}_{(p)}$ & $h^{2}$ & $c^{2}$ \\
\hline Model 1 & 681.905 & & 2864.780 & 3546.685 & 0.192 & \\
Model 2 & 317.270 & 332.752 & 2816.178 & 3466.200 & 0.091 & 0.0960 \\
\hline
\end{tabular}

- Model 4: bivariate animal model, considering DO as different correlated traits for young cows (first and second calving) and for adult cows (three or more calvings), and including the additive genetic effects $(u)$ and the covariance between these $\left(\operatorname{cov}_{(u u)}\right)$ as dependent on the relationship matrix, the permanent environment effects $(c)$, the covariance between these $\left(\operatorname{cov}_{(c c)}\right)$, and the residual $(e)$.

- Model 5: a bivariate animal model like model 4 used to characterise the genetic relationships between DO and, respectively, CI, GL, and CD.

\section{Results}

Days from calving to conception in the Asturiana de los Valles breed had a mean of 103.2 \pm 61.1 days and median and mode of 85 and 69 days, respectively. Table 1 describes the frequencies of the reproductive performance in the analysed database according to the number of calvings of the dam. Fifty-two percent of the available dams became pregnant within a range of 87 days from calving. These cows are expected to

Table 1

Number of data $(n)$ and distribution (in percentages) of the available records of DO

\begin{tabular}{lcccc}
\hline Days to conception & First calving & Second calving & From three to nine calvings & 10 or more calvings \\
\hline$n$ & 3250 & 3416 & 13783 & 900 \\
45 days or fewer (\%) & 5.88 & 8.34 & 10.53 & 8.56 \\
From 46 to 66 days (\%) & 14.62 & 19.58 & 22.84 & 19.67 \\
From 67 to 87 days (\%) & 17.97 & 21.25 & 22.75 & 23.00 \\
From 88 to 108 days (\%) & 15.32 & 15.13 & 14.95 & 14.89 \\
From 109 to 129 days (\%) & 10.15 & 10.66 & 20.92 & 10.33 \\
130 days or more (\%) & 36.06 & 25.03 & $97.79 \pm 57.84^{\mathrm{c}}$ & 23.56 \\
Mean DO ( \pm S.D.) & $122.42 \pm 68.55^{\mathrm{a}}$ & $106.77 \pm 62.73^{\mathrm{b}}$ & $388.07 \pm 61.85^{\mathrm{c}}$ & $103.03 \pm 58.85^{\mathrm{d}}$ \\
Mean calving interval $( \pm$ S.D.) & $411.17 \pm 73.32^{\mathrm{a}}$ & $394.55 \pm 65.02^{\mathrm{b}}$ & $396.30 \pm 63.29^{\mathrm{b}}$ \\
Mean gestation length $( \pm$ S.D.) & $286.26 \pm 5.71^{\mathrm{a}}$ & $286.88 \pm 5.61^{\mathrm{b}}$ & $287.66 \pm 5.69^{\mathrm{c}}$ & $288.09 \pm 5.94^{\mathrm{d}}$ \\
Mean calving date $( \pm$ S.D.) & $20.14 \pm 50.04^{\mathrm{a}}$ & $19.23 \pm 102.16^{\mathrm{a}}$ & $16.35 \pm 114.90^{\mathrm{a}}$ & $17.59 \pm 128.73^{\mathrm{a}}$ \\
\hline
\end{tabular}

Additionally, mean and standard deviation (S.D.) for DO, calving interval, gestation length, and calving date are given.

Unequal superscripts express significant differences between means for $p<0.05$ assessed by means of Duncan's test using SAS (1999). 
Table 3

Genetic $(u)$, error $(e)$, and phenotypic ( $p$ ) variances, heritability, genetic covariances (on diagonal), and genetic correlation (below diagonal) for DO in the Asturiana de los Valles breed analysed by means of model 3

\begin{tabular}{|c|c|c|c|c|c|c|c|c|}
\hline & \multirow[t]{2}{*}{$\operatorname{Var}_{(u)}$} & \multirow[t]{2}{*}{$\operatorname{Var}_{(e)}$} & \multirow[t]{2}{*}{$\operatorname{Var}_{(p)}$} & \multirow[t]{2}{*}{$h^{2}$} & \multicolumn{4}{|c|}{ Covariances and genetic correlations } \\
\hline & & & & & $\begin{array}{l}\text { First } \\
\text { calving }\end{array}$ & $\begin{array}{l}\text { Second } \\
\text { calving }\end{array}$ & $\begin{array}{l}\text { From three to } \\
\text { nine calvings }\end{array}$ & $\begin{array}{l}10 \text { or more } \\
\text { calvings }\end{array}$ \\
\hline First calving & 717.261 & 3550.734 & 4267.995 & 0.168 & & 717.327 & 539.806 & 355.94 \\
\hline Second calving & 722.563 & 2953.282 & 3675.845 & 0.197 & 0.996 & & 566.545 & 381.94 \\
\hline From three to nine calvings & 544.025 & 2655.081 & 3199.106 & 0.170 & 0.864 & 0.904 & & 401.95 \\
\hline 10 or more calvings & 307.108 & 3050.745 & 3357.843 & 0.091 & 0.758 & 0.811 & 0.983 & \\
\hline
\end{tabular}

attain the desirable performance of one calving a year. However, a high proportion of the dams (23\%) was very far from this objective and remained open after 130 days after calving. This was especially true for heifers (36\%), which have an average DO 19 days longer than the overall mean. Mean and standard deviations computed for CI, GL, and CD were, respectively, $393.28 \pm 64.99,287.34 \pm 5.74$, and $17.48 \pm 106.02$ days. DO and CI tended to increase with calving number, while GL tended to shorten. CD did not show significant differences according calving number.

Table 2 shows the results of the genetic analysis of DO carried out using univariate models. The genetic variance estimated using model 2 was considerably lower than that obtained with model 1 , leading to a reduction in heritability from 0.19 (model 1) to 0.09 (model 2). A likelihood ratio test indicated that error variances remained substantially the same in models 1 and 2, illustrating confusion between genetic and environmental components. The permanent environment estimated by means of model 2 reaches $9.6 \%$. When DO was analysed using a multivariate model (model 3), genetic variances were not as reduced as those of model 2. In Table 3, the heritabilities estimated for DO ranged between 0.091 for the oldest cows (10 or more calvings) and 0.197 for second calving cows. Heifers and adult cows (from three to nine calvings) have a similar heritability of around $17 \%$. The heritability estimated for DO in younger cows was higher (0.154) than that estimated for adult cows (0.132) (Table 4). In addition, the genetic correlation between these traits was 1 , showing that DO was genetically the same trait, regardless of the parity of the cow. Furthermore, Table 4 shows that $c^{2}$ affects younger cows $(9 \%)$ to a higher extent than adult cows (4\%).

A bivariate model was used to ascertain the genetic relationships between DO and, respectively, $\mathrm{CI}$, GL, and CD. Table 5 shows the phenotypic correlation $\left(r_{p}\right)$ between each pair of analysed traits, the heritability for the direct genetic effect for DO and the other traits, the corresponding value for the permanent environmental effect, the genetic correlation between direct $\left(r_{u u}\right)$ genetic effects, and the correlation between permanent environmental effects $\left(r_{c c}\right)$. Genetic correlation between DO and CI was 1.0 , while genetic correlation between DO and the other reproductive traits was negative from -0.089 for GL to -0.308 for CD. Heritability estimated for DO was around 0.09 when this trait was analysed with both GL and $\mathrm{CD}$, while that obtained when analysed with CI was higher (0.135). Permanent environment obtained for DO was around 0.10 except for the analysis with CI (0.258). Permanent environment of DO was highly correlated with those

Table 4

Genetic $(u)$, permanent environment $(c)$, error $(e)$, and phenotypic $(p)$ variances, heritability, genetic covariances (on diagonal), and genetic correlation (below diagonal) for DO in the Asturiana de los Valles breed analysed by means of model 4

\begin{tabular}{|c|c|c|c|c|c|c|c|c|}
\hline & $\operatorname{Var}_{(u)}$ & $\operatorname{Cov}_{(u)}$ & $\operatorname{Var}_{(c)}$ & $\operatorname{Var}_{(e)}$ & $\operatorname{Var}_{(p)}$ & $h^{2}$ & $c^{2}$ & $r_{(u u)}$ \\
\hline First and second calvings & 624.764 & 514.085 & 369.711 & 3070.69 & 3743.995 & 0.154 & 0.091 & 1.000 \\
\hline Three or more calvings & 423.013 & & 118.404 & 2663.62 & 3358.601 & 0.132 & 0.037 & \\
\hline
\end{tabular}


Table 5

Parameters resulting from the analysis of DO together with CI, GL, and CD, respectively, in the Asturiana de los Valles beef cattle breed by means of a bivariate model

\begin{tabular}{|c|c|c|c|c|c|c|c|}
\hline Analysis & $r_{p}$ & $\begin{array}{l}\mathrm{h}^{2} \\
\mathrm{DO}\end{array}$ & $\begin{array}{l}h^{2} \\
\text { other }\end{array}$ & $r_{u u}$ & $\begin{array}{l}\mathrm{c}^{2} \\
\mathrm{DO}\end{array}$ & $\begin{array}{l}c^{2} \\
\text { other }\end{array}$ & $r_{c c}$ \\
\hline $\mathrm{DO}-\mathrm{CI}$ & 0.396 & 0.135 & 0.106 & 1.0 & 0.258 & 0.193 & 1.0 \\
\hline DO-GL & 0.002 & 0.090 & 0.115 & -0.089 & 0.099 & 0.040 & 0.087 \\
\hline $\mathrm{DO}-\mathrm{CD}$ & -0.005 & 0.086 & 0.140 & -0.308 & 0.102 & 0.682 & 0.0 \\
\hline
\end{tabular}

estimated for CI (1.0), while there was little or no correlation with GL (0.087) and CD (0.0).

\section{Discussion}

Mean values and trends according to calving number computed for the reproductive traits analysed in the present work are consistent with others reported previously in Asturiana de los Valles breed (Goyache et al., 1995, 2002; Goyache and Gutiérrez, 2001; Gutiérrez et al., 2002). Heritabilities estimated for DO in the present study were substantially higher than those usually reported for dairy cattle, most being $5 \%$ or less (Grosshans et al., 1997; Kirkpatrick, 1998; Abdallah and McDaniel, 2000). However, Koots et al. (1994) reported that mean heritabilities of reproductive traits in beef cattle are, in general, twofold or more than those calculated in dairy cattle. Asturiana de los Valles breed had a high genetic variability for most productive and reproductive traits analysed previously (Gutiérrez et al., 1997; Goyache and Gutiérrez, 2001, Goyache et al., 2003). The large genetic variances estimated in Asturiana de los Valles breed for reproductive traits could be caused by some confounding between the genetic effect of the sire and environmental factors related with herd. However, the structure of analysed data would lead to reject this hypothesis because of the wide use of artificial insemination and the favourable distribution of sires of cow between herds.

Genetic correlations estimated between first and second calving DOs and between adult and older cow DOs were roughly 1 , showing that DO was the same trait in genetic terms, at least for these pairs. At any rate, the genes affecting DO in younger and adult reproductive ages are substantially the same (Philipsson, 1981) because genetic correlations between the DO of young and adult cows ranged from 0.81 to 0.90 . The genetic correlations estimated in the present study for DO in different parities were higher than those estimated for DO in dairy cattle, which are generally somewhat lower than 0.70 (Jansen et al., 1987). Genetic variances for DO in dairy cattle seem to increase with parity number (Jansen et al., 1987). Grosshans et al. (1997) in New Zealand dairy cattle reported lesser genetic variance in second calving cows than in heifers both for DO and CI. In the present analysis, genetic variances, but also permanent environmental and the other components of the phenotypical variances, were higher for the younger cows (see Tables 3 and 4). Cows were not required to have a first calving observation. Then, the estimation of the genetic variances for adult cows under multivariate models could be biased downwards due to management decisions carried out by the farmers (i.e., selection of the dams according to their reproductive performance). Nevertheless, in the Asturiana de los Valles breed, there is no strict selection policy according to reproductive performance. As previously reported for other Spanish beef cattle breed such as Retinta (López de Torre and Brinks, 1990), management practices are mostly traditional and open cows usually remain in the herds. Furthermore, the effect in dairy cattle of a strict culling policy for fertility has been shown to have a negligible effect on DO performance and on the estimation of genetic parameters affecting this trait (Philipsson, 1981; Jansen et al., 1987; Lee et al., 1997).

The genetic situation of DO in Asturiana de los Valles breed was confirmed by the analysis shown in Table 4. Genetic variability was higher in younger cows. Moreover, DO performance of heifers and second calving cows was affected by the same environmental factors as those affecting older cows. Improvement of reproductive performance is possible by selecting heifers on the basis of their DO scores. The present results suggest that the lower genetic and phenotypic variances estimated for cows with three or more calvings are due to a more regular reproductive performance of the adult cows rather than a bias produced from selection pressure for reproductive performance. Moreover, reproductive performance of adult cows is less affected by environmental factors than that of younger cows. 
The present results showed that DO and CI are the same trait in genetic terms (Table 5). Estimation of genetic correlations between DO and CI is scarce. Grosshans et al. (1997) reported a genetic correlation between DO and CI of 0.98 in New Zealand dairy cattle. The higher heritability showed by DO in the present analysis when analysed with CI can be a result of the high genetic correlation found. The heritabilities estimated for DO when analysed with both GL and $\mathrm{CD}$ were very similar (around 9\%). Moreover, the heritabilities estimated for CI, GL, and DO were consistent and slightly lower than those obtained previously for the same trait in Asturiana de los Valles breed analysing different databases $(0.12$ for CI, 0.15 for GL, and 0.21 for CD) (Goyache and Gutiérrez, 2001; Gutiérrez et al., 2002). Moreover, the genetic correlation estimated between DO and CD $(-0.308)$ was similar to that reported for CI and CD $(-0.285)$ in Asturiana de los Valles breed by Gutiérrez et al. (2002). The differences between the estimates above can be a result of the inclusion of $c^{2}$ in Model 5. In previous papers, $c^{2}$ was not included in the model (Gutiérrez et al., 2002) or was assumed to be negligible (Goyache and Gutiérrez, 2001). The present estimates of $c^{2}$ were higher than other estimates in the literature (see Rust and Groeneveld, 2001 for a recent review), especially for CD. In the present study, $c^{2}$ for $C D$ reached 0.68 . This value was found to be consistent in an array of analytical models fitted to estimate the genetic parameters involved in the present work.

\section{Conclusions}

The present study characterises DO as a trait with considerable genetic variability, relative to that usually found for reproduction traits, especially in heifers and second calving cows. Sampling, besides the strong genetic correlation found for the trait in different parities, may be the main cause for the differences between repeated estimates of heritability. In Asturiana de los Valles breed, there is no selection policy according to reproductive performance. The genetic correlation between parities (roughly 1) means that selection of heifers according to DO would be of great value in progeny testing of bulls because breeding values may readily be calculated in advance of other reproductive traits. In this sense, DO seems to be the same genetic trait as CI. In addition, the genetic relationship between DO and CD was similar to that reported earlier for CI and CD (Gutiérrez et al., 2002). However, recording of DO is considerably less timeconsuming than recording CI. This could allow computing DO breeding values at the same time as productive traits such as weaning growth traits. Further research will be needed to ascertain the genetic relationships of DO with preweaning growth traits so as to evaluate the usefulness of including DO in the breeding goal of beef cattle.

\section{Acknowledgements}

This paper was partially funded by a grant from MCyT and FEDER (no. 1FD97-1633) and the Regional Government of the Principado de Asturias. The authors would like to thank Dr. Enrique Gómez for his kind support.

\section{References}

Abdallah, J.M., McDaniel, B.T., 2000. Genetic parameters and trends of milk, fat, days open and body weight after calving in North Carolina experimental herds. J. Dairy Sci. 83, 13641370 .

Freeman, A.E., 1984. Secondary traits: sire evaluation and the reproductive complex. J. Dairy Sci. 67, 449-458.

Goyache, F., Gutiérrez, J.P., 2001. Heritability of reproductive traits in Asturiana de los Valles beef cattle breed. Arch. Tierz. 44, 489-496.

Goyache, F., Gutiérrez, J.P., Dunner, S., Cañón, J., 1995. Principales efectos ambientales que influyen sobre el intervalo entre partos de la raza Asturiana de los Valles. Arch. Zootec. 44, 317-334.

Goyache, F., Fernández, I., Álvarez, I., Royo, L.J., Gutiérrez, J.P., 2002. Gestation length in the Asturiana de los Valles beef cattle breed and its relationship with birth weight and calving ease. Arch. Zootec. 51, 431-439.

Goyache, F., Gutiérrez, J.P., Álvarez, I., Fernández, I., Royo, L.J., Gómez, E., 2003. Genetic analysis of calf survival at different preweaning ages in beef cattle. Livest. Prod. Sci. 83, 13-20.

Grosshans, T., Xu, Z.Z., Burton, L.J., Johnson, D.L., MacMillan, K.L., 1997. Performance and genetic parameters for fertility of seasonal dairy cows in New Zealand. Livest. Prod. Sci. 51, $41-51$.

Gutiérrez, J.P., Goyache, F., 2002. Estimation of genetic parameters of type traits in beef cattle. J. Anim. Breed. Genet. 119, 93-100.

Gutiérrez, J.P., Goyache, F., Cañón, J., 1997. Estimation of direct and maternal genetic parameters for preweaning traits in the 
Asturiana de los Valles beef cattle breed through animal and sire models. J. Anim. Breed. Genet. 114, 261-266.

Gutiérrez, J.P., Álvarez, I., Fernández, I., Royo, L.J., Díez, J., Goyache, F., 2002. Genetic relationships between calving date, calving interval, age at first calving and type traits in beef cattle. Livest. Prod. Sci. 78, 215-222.

Gutiérrez, J.P., Fernández, I., Royo, L.J, Álvarez, I., Goyache, F., 2003. Factores ambientales y genéticos de influencia en el periodo vacío entre parto y concepción en la raza Asturiana de los Valles. ITEA 24 Vol extra II, 507-509.

Jansen, J., Van der Werf, J., De Boer, W., 1987. Genetic relationships between fertility traits for dairy cows in different parities. Livest. Prod. Sci. 17, 337-349.

Kirkpatrick, B.W., 1998. Genetics and biology of reproduction in cattle. In: Fries, R., Ruvinsky, A. (Eds.), The Genetics of Cattle, 391-410 pp.

Koots, K.R., Gibson, J.P., Smith, C., Wilton, J.W., 1994. Analyses of published genetic parameter estimates for beef production traits: 1. Heritability. Anim. Breed. Abstr. 62, 309-338.
Lee, J.K., Van Raden, P.M., Norman, H.D., Wiggans, G.R., Meinert, T.R., 1997. Relationship of yield during early lactation and days open during current lactation with 305-day yield. J. Dairy Sci. $80,771-776$.

López de Torre, G., Brinks, J.S., 1990. Some alternatives to calving date and interval as measures of fertility in beef cattle. J. Anim. Sci. 68, 2650-2657.

Meyer, K., 1997. An "average information" restricted maximum likelihood algorithm for estimating reduced rank genetic covariance matrices or covariance functions for animal models with equal design matrices. Genet. Sel. Evol. 29, 97-116.

Philipsson, J., 1981. Genetic aspects of female fertility in dairy cattle. Livest. Prod. Sci. 8, 307-319.

Rust, T., Groeneveld, E., 2001. Variance component estimation on female fertility traits in beef cattle. S. Afr. J. Anim. Sci. 31, $131-141$

SAS, 1999. SAS/STAT V 8.2 User's Guide: Statistics. SAS Institute, Cary, NC, USA. 